\title{
Article
}

\section{Long-Term Tacrolimus Blood Trough Level and Patient Survival in Adult Liver Transplantation}

\author{
Chih-Yang Hsiao ${ }^{1,2,3,4} \oplus$, Ming-Chih Ho ${ }^{2,3}$, Cheng-Maw Ho ${ }^{3} \oplus$, Yao-Ming Wu ${ }^{2,3}$, Po-Huang Lee ${ }^{3,5}$ \\ and Rey-Heng $\mathrm{Hu}^{2,3,4, *}$ \\ 1 Graduate Institute of Clinical Medicine, College of Medicine, National Taiwan University, \\ Taipei City 110, Taiwan; cyhsiao1102@gmail.com \\ 2 Department of Surgery, National Taiwan University College of Medicine, Taipei City 110, Taiwan; \\ mcho1215@ntu.edu.tw (M.-C.H.); wyaoming@gmail.com (Y.-M.W.) \\ 3 Department of Surgery, National Taiwan University Hospital, Taipei City 110, Taiwan; \\ miningho@ntu.edu.tw (C.-M.H.); pohuang1115@ntu.edu.tw (P.-H.L.) \\ 4 Department of Traumatology, National Taiwan University Hospital, Taipei City 110, Taiwan \\ 5 Department of Surgery, E-Da Hospital, I-Shou University, Kaohsiung 886, Taiwan \\ * Correspondence: rhhu@ntu.edu.tw; Tel.: +886-2-2312-3456 (ext. 65106)
}

Citation: Hsiao, C.-Y.; Ho, M.-C.; Ho, C.-M.; Wu, Y.-M.; Lee, P.-H.; Hu, R.-H. Long-Term Tacrolimus Blood Trough Level and Patient Survival in Adult Liver Transplantation. J. Pers. Med. 2021, 11, 90. https://doi.org/ 10.3390/jpm11020090

Academic Editor: Aaron W. Bell

Received: 30 December 2020

Accepted: 29 January 2021

Published: 1 February 2021

Publisher's Note: MDPI stays neutral with regard to jurisdictional claims in published maps and institutional affiliations.

\begin{abstract}
Tacrolimus is the most widely used immunosuppressant in liver transplant (LT) patients. However, the ideal long-term target level for these patients is unknown. This retrospective study aimed to investigate the impact of tacrolimus blood concentration five years after LT on long-term patient survival outcomes in adult LT recipients. Patients who underwent LT between January 2004 and July 2014 at a tertiary medical center were included in this study $(n=189)$. The mean tacrolimus blood concentrations of each patient during the fifth year after LT were recorded and the overall survival rate was determined. A multivariate analysis of factors associated with long-term survival was conducted using a Cox's model. The median follow-up period was 9.63 years, and 144 patients $(76.2 \%)$ underwent live donor LT. Sixteen patients died within 5 years of LT. In the Cox's model, patients with a mean tacrolimus blood trough level of 4.6-10.2 ng/mL had significantly better long-term survival than those with a mean tacrolimus blood trough level outside this range (estimated hazard ratio $=4.76 ; 95 \%$ confidence interval: $1.34-16.9, p=0.016$ ). Therefore, a tacrolimus level no lower than $4.6 \mathrm{ng} / \mathrm{mL}$ would be recommended in adult LT patients.
\end{abstract}

Keywords: Cox's model; immunosuppressant; liver transplantation; survival; tacrolimus

\section{Introduction}

Liver transplantation (LT) has become a mature treatment of end-stage liver disease in clinical practice [1]. The continuous improvement of effective immunosuppression treatments has led to a significant improvement in patient and graft survival in recent years [2]. Calcineurin inhibitors are the cornerstone of immunosuppression in LT [3], and tacrolimus is currently the mainstay of initial and maintenance immunosuppression therapies [4-6]. Tacrolimus reduces the incidence and severity of early and late T-cell mediated rejection by inhibiting T-cell production of interleukin-2 [5,6]. However, the long-term use of immunosuppressants leads to an increasing burden of toxicity. The reported toxic effects of calcineurin inhibitors include infections, chronic renal insufficiency, metabolic diseases (such as hyperlipidemia, hypertension, and diabetes mellitus), and malignancy [7-9], which, along with cardiovascular diseases, have been reported to be the major causes of morbidity and mortality after LT $[3,10]$. However, most LT patients cannot withdraw from lifelong immunosuppression therapy; the only exceptions are a few selected patients participating in experimental trials [11,12].

It is a clinical challenge to design a well-balanced immunosuppressive regimen for LT recipients. Tacrolimus has a narrow therapeutic dose range and its blood levels should 
be carefully monitored. The Advagraf (tacrolimus prolonged-release hard capsules) recommendation for adult LT patients is a blood trough level of $5-20 \mathrm{ng} / \mathrm{mL}$ in the early post-transplant period and $5-15 \mathrm{ng} / \mathrm{mL}$ during subsequent maintenance therapy. Nevertheless, the current recommendations from the clinical practice guidelines for the ideal tacrolimus level in adults after LT remain controversial. The American Association for the Study of Liver Diseases (AASLD) recommends a target blood trough level of 5-10 $\mathrm{ng} / \mathrm{mL}$ for tacrolimus three months after LT [13]. The Consensus on Managing Modifiable Risk in Transplantation Group (COMMIT) recommends that the target tacrolimus blood trough levels be $6-10 \mathrm{ng} / \mathrm{mL}$ during the first month after LT and decrease to $4-8 \mathrm{ng} / \mathrm{mL}$ thereafter, except when used in combination with mammalian target of rapamycin (mTOR) inhibitors [14]. Moreover, the International Liver Transplant Society (ILTS) consensus statement on immunosuppression in LT recipients recommends the target blood trough levels of tacrolimus be $6-10 \mathrm{ng} / \mathrm{mL}$ three months after LT, lower than $5 \mathrm{ng} / \mathrm{mL} 12$ months after LT, and decrease to $3 \mathrm{ng} / \mathrm{mL}$ thereafter, resulting in a blood trough level just above the lower limit of detection five years after LT [15]. However, the impact of the long-term tacrolimus blood trough level on the outcomes of the LT recipients remains unclear. This study aimed to suggest an appropriate tacrolimus blood trough level for adult patients five years after LT.

\section{Materials and Methods}

This study was approved by the Institutional Review Board of National Taiwan University Hospital and was conducted according to the Declaration of Helsinki. A total of 286 patients who underwent LT at 18 years or older at a tertiary medical center from January 2004 to July 2014 were recruited for this study. Patients who died within 5 years of LT, were lost to follow-up, or did not use tacrolimus-based calcineurin inhibitor for immunosuppressant therapy were excluded from this study (Figure 1). In addition, those who received mTOR inhibitor treatment were excluded, as mTOR inhibitors are typically used as a combination therapy to reduce the required dose of tacrolimus. The final analysis included 189 patients. All eligible patients were followed up for more than five years until August 2019. Patients who underwent a LT due to liver cancer met the Milan criteria (before 2006) or the criteria of the University of California, San Francisco (since 2006) at the time of LT. All patients received regular monthly or bi-monthly follow-ups at the outpatient clinic after LT. Routine blood examinations for the tacrolimus blood trough level, liver function, and renal function were conducted at each visit, and abdominal sonography was performed every 6 to 12 months.

The patients' medical records were reviewed retrospectively to extract demographic and clinical data, including patient characteristics, laboratory tests, and survival outcomes. The serum bilirubin and creatinine data at the end of the fifth year after LT were used in this study. The tacrolimus level used in this study was the mean of the values obtained at the three follow-up visits during the fifth year after LT.

The immunosuppression protocol for adult LT patients consisted of tacrolimus, mycophenolate mofetil, and steroids. Tacrolimus was administered orally beginning on the first day after LT, and the dose was adjusted to achieve the desired therapeutic drug level. Basiliximab was administered immediately before graft reperfusion and on the fourth day after LT for induction therapy. A 500-mg intravenous bolus of methylprednisolone was administered immediately before reperfusion of the liver graft and was tapered to oral prednisolone over one week and reduced to withdrawal after six months.

All statistical analyses were performed using R 4.0.2 software (R Foundation for Statistical Computing, Vienna, Austria). Statistical significance was set at $p \leq 0.05$. Continuous variables are presented as mean \pm standard deviation (SD) and median (interquartile range, $\mathrm{IQR}$ ), and categorical variables are presented as frequency (percentage, \%). The survival curve was estimated by the Kaplan-Meier method. A univariate analysis was conducted to examine the differences in the distributions of continuous variables, categorical variables, and survival outcomes between the surviving and deceased liver recipients five years 
after LT using the Wilcoxon rank-sum test, Chi-square test, Fisher's exact test, or log-rank test as appropriate for the data type. A multivariate analysis was performed to estimate the adjusted effects of risk factors or prognostic factors on the survival outcome using a multiple Cox's proportional hazards model.

\section{Enrollment:}

286 consecutive patients underwent

liver transplantations from 2 January

2004 to 15 July 2014

\section{2 patients were excluded:}

58 deaths within 5 years

4 lost to follow-up within 5 years

Inclusion:

224 patients underwent liver transplantations with long-term survival $\geq 5$ years

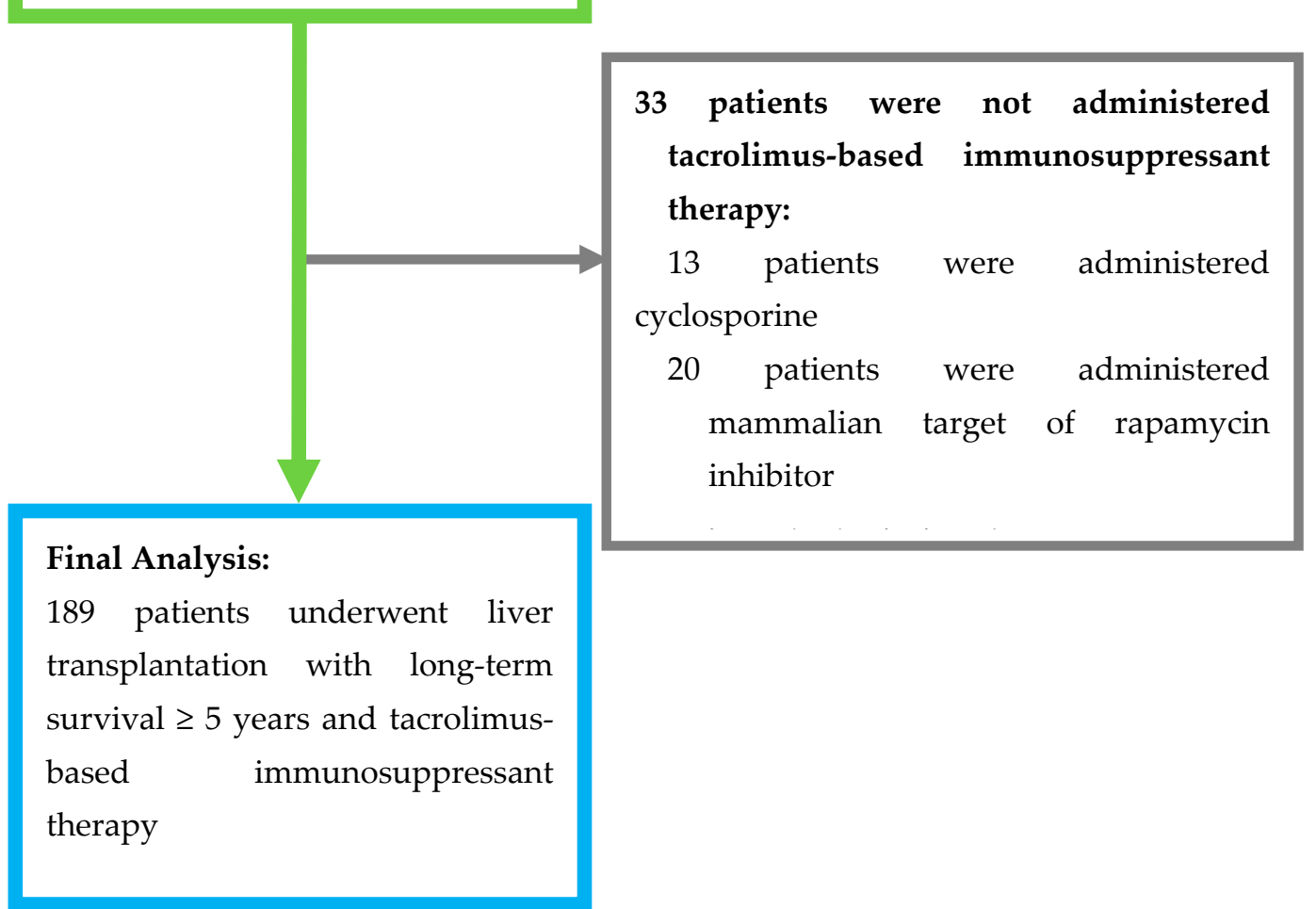

Figure 1. Patient flow diagram.

To ensure a good quality of regression analysis, the model-fitting techniques for variable selection, goodness-of-fit (GOF) assessment, and regression diagnostics and remedies were used in our regression analysis. Specifically, the stepwise variable selection procedure 
(with iterations between the forward and backward steps) was applied to obtain the best final regression model using the My.stepwise package of the R software [16]. All significant and non-significant relevant covariates from the univariate analysis (listed in Table 1) and some of the interaction terms were used in the multivariate analysis. The significance levels for entry and for stay were set to 0.15 for being conservative. With the aid of substantive knowledge, the best candidate final regression model was identified manually by dropping the covariates with $p$ value $>0.05$ one at a time until all regression coefficients were significantly different from 0 . To assess the GOF of the fitted Cox's model, the concordance and adjusted generalized $R^{2}$ [17] were examined. A concordance $\geq 0.7$ and an adjusted generalized $R^{2}>0.15$ indicated an acceptable level of discrimination, power, and fitness.

Table 1. Univariate analysis for comparing the distributions of the demographic and clinical characteristics between the alive and dead adult liver recipients after five years of liver transplantations.

\begin{tabular}{|c|c|c|c|c|}
\hline Variable & $\begin{array}{l}\text { All Patients } \\
\quad(n=189)\end{array}$ & $\begin{array}{c}\text { Alive } \\
(n=173)\end{array}$ & $\begin{array}{c}\text { Dead } \\
(n=16)\end{array}$ & $p$ Value \\
\hline Gender & & & & 0.7899 \\
\hline Male & $121(64.0)$ & $110(90.9)$ & $11(9.1)$ & \\
\hline Female & $68(36.0)$ & $63(92.6)$ & $5(7.4)$ & \\
\hline Age at LT (years) & $52.7 \pm 9.6$ & $52.6 \pm 9.5$ & $53.4 \pm 10.7$ & 0.6672 \\
\hline Body weight at LT (kg) & $64.9 \pm 12.2$ & $65.0 \pm 12.3$ & $63.7 \pm 12.1$ & 0.4459 \\
\hline Blood type & & & & 0.8719 \\
\hline $\mathrm{O}$ & $79(41.8)$ & $73(92.4)$ & $6(7.6)$ & \\
\hline A & $51(27.0)$ & $46(90.2)$ & $5(9.8)$ & \\
\hline $\mathrm{B}$ & $42(22.2)$ & $39(92.9)$ & $3(7.1)$ & \\
\hline $\mathrm{AB}$ & $17(9.0)$ & $15(88.2)$ & $2(11.8)$ & \\
\hline Graft type & & & & 1.0000 \\
\hline Living donor & $144(76.2)$ & $132(91.7)$ & $12(8.3)$ & \\
\hline Deceased donor & $45(23.8)$ & $41(91.1)$ & $4(8.9)$ & \\
\hline \multicolumn{5}{|l|}{ Etiology for LT } \\
\hline Liver malignancy (HCC) & $72(38.1)$ & $66(91.7)$ & $6(8.3)$ & 1.0000 \\
\hline Alcoholic cirrhosis & $17(9.0)$ & $16(94.1)$ & $1(5.9)$ & 1.0000 \\
\hline HBV cirrhosis & $100(52.9)$ & $92(92.0)$ & $8(8.0)$ & 1.0000 \\
\hline HCV cirrhosis & $42(22.2)$ & $38(90.5)$ & $4(9.5)$ & 0.7577 \\
\hline Fulminant hepatitis & $23(12.2)$ & $23(100)$ & $0(0)$ & 0.2259 \\
\hline Autoimmune disease & $14(7.4)$ & $11(78.6)$ & $3(21.4)$ & 0.1017 \\
\hline Biliary atresia & $5(2.6)$ & $5(100)$ & $0(0)$ & 1.0000 \\
\hline Other & $10(5.3)$ & $9(90)$ & $1(10)$ & 0.5964 \\
\hline Total bilirubin (mg/dL) & $0.973 \pm 0.51$ & $0.958 \pm 1.53$ & $1.133 \pm 0.69$ & 0.6260 \\
\hline Total bilirubin $>1 \mathrm{mg} / \mathrm{dL}$ & $60(31.7)$ & $53(88.3)$ & $7(11.7)$ & 0.2770 \\
\hline Total bilirubin $>2 \mathrm{mg} / \mathrm{dL}$ & $11(5.8)$ & $9(81.8)$ & $2(18.2)$ & 0.2360 \\
\hline Creatinine $(\mathrm{mg} / \mathrm{dL})$ & $1.391 \pm 1.25$ & $1.279 \pm 0.96$ & $2.6 \pm 2.74$ & 0.0201 * \\
\hline Creatinine $>1.5 \mathrm{mg} / \mathrm{dL}$ & $31(16.4)$ & $23(74.2)$ & $8(25.8)$ & 0.0010 * \\
\hline ESRD & $5(2.6)$ & $2(40.0)$ & $3(60.0)$ & 0.0050 * \\
\hline Tacrolimus mean level (ng/mL) & $5.249 \pm 1.71$ & $5.263 \pm 1.53$ & $5.096 \pm 3.12$ & 0.9787 \\
\hline Tacrolimus level $<5 \mathrm{ng} / \mathrm{mL}$ & $93(49.2)$ & $82(88.2)$ & $11(11.8)$ & 0.1216 \\
\hline Tacrolimus level $<4 \mathrm{ng} / \mathrm{mL}$ & $44(23.3)$ & $36(81.8)$ & $8(18.2)$ & $0.0136^{*}$ \\
\hline Tacrolimus level < $3 \mathrm{ng} / \mathrm{mL}$ & $11(5.8)$ & $9(81.8)$ & $2(18.2)$ & 0.2356 \\
\hline
\end{tabular}

Data are presented as mean \pm standard deviation (SD) for continuous variables and frequency (percentage, \%) for categorical variables. The $p$-values of statistical tests were calculated using the Wilcoxon rank-sum test for continuous variables and the Fisher's exact test for categorical variables. ${ }^{*} p$ value $\leq 0.05$. Abbreviations: LT, liver transplantation; HCC, hepatocellular carcinoma; HBV, hepatitis B virus; HCV, hepatitis C virus; Total bilirubin, serum total bilirubin level; Creatinine, serum creatinine level; and ESRD, end-stage renal disease (defined by receiving hemodialysis regularly).

Moreover, the smoothing option "pspline" (for the smoothing splines using a "pspline" basis) was specified inside the coxph function of the survival package to smooth the effects of continuous covariates on the log-hazard rate of the simple and multiple Cox's proportional hazards models in R. Then, the termplot function of the stats package was used to plot the smoothed effects of the continuous covariates on the log-hazard 
rate in $\mathrm{R}$ [18]. The regression diagnostics for the verification of proportional hazards assumption, residual analysis, detection of influential cases, and a multicollinearity check were applied to discover any model or data problems. A variance inflating factor (VIF) $\geq 10$ in continuous covariates or VIF $\geq 2.5$ in categorical covariates indicated the occurrence of the multicollinearity problem among some of the covariates in the fitted regression model.

\section{Results}

\subsection{Patients' Demographic and Clinical Characteristics}

The median follow-up duration was 9.63 years (IQR: 7.2-11.4 years), and the mean follow-up was $9.58 \pm 2.74$ years. A total of 121 males $(64.0 \%)$ and 68 females $(36.0 \%)$ were included in this study (Table 1 ). The median age at LT was 54.26 years (IQR: $48.63-58.58$ years, range: $18.3-73.1$ years), and the mean age at LT was $52.7 \pm 9.6$ years. Among the 189 patients, $114(76.2 \%)$ underwent living donor transplants and $45(23.8 \%)$ underwent deceased donor transplants. The main indications for LT were hepatitis B virus (HBV) cirrhosis $(52.9 \%)$, hepatocellular carcinoma $(38.1 \%)$, hepatitis $\mathrm{C}$ virus (HCV) cirrhosis $(22.2 \%)$, and fulminant hepatitis (12.2\%). The median of the mean tacrolimus blood trough level during the fifth year after LT was $5.0 \mathrm{ng} / \mathrm{mL}$ (IQR: 4.12-6.33 $\mathrm{ng} / \mathrm{mL}$ ), and the mean tacrolimus blood trough level was $5.249 \pm 1.71 \mathrm{ng} / \mathrm{mL}$. The mean tacrolimus blood trough level was $\geq 5 \mathrm{ng} / \mathrm{mL}$ in 96 patients $(50.8 \%)$ and $<5 \mathrm{ng} / \mathrm{mL}$ in 93 patients $(49.2 \%)$, including 44 patients $(23.3 \%)$ with a mean tacrolimus blood trough level $<4 \mathrm{ng} / \mathrm{mL}$ and 11 patients $(5.8 \%)$ with a mean tacrolimus blood trough level $<3 \mathrm{ng} / \mathrm{mL}$. No significant differences in gender, age at LT, body weight, blood type, graft type, etiology of LT, or serum total bilirubin were found between the deceased and surviving LT recipients $(p>0.05)$. However, serum creatinine levels $>1.5 \mathrm{mg} / \mathrm{dL}(23 / 173$ vs. $8 / 16, p=0.001)$, end-stage renal disease $(2 / 173$ vs. $3 / 16, p=0.005)$, and mean tacrolimus blood trough levels $<4 \mathrm{ng} / \mathrm{mL}$ $(36 / 173$ vs. $8 / 16, p=0.014)$ were significantly more common among deceased LT recipients compared to survivors. The causes of death included malignancies $(n=5)$, graft failures $(n=4)$, infection $(n=4)$, cerebrovascular accidents $(n=2)$, and duodenal ulcer bleeding $(n=1)$ (Table 2). The distribution of the tacrolimus trough level stratified by the etiology and cause of death among the 16 dead patients was shown in the box plot of Figure 2. There was no statistical significance in the tacrolimus trough level between the different causes of death $(p=0.3823)$.

Table 2. The causes of 16 deaths since 5 years after adult liver transplantations.

\begin{tabular}{cc}
\hline Causes of Deaths & Number of Subjects \\
\hline Malignancy & $5(31.25 \%)$ \\
De novo: Multiple myeloma, bladder cancer, \\
colon cancer, prostate cancer \\
Recurrent: Hepatocellular carcinoma & 4 \\
Graft failure & 1 \\
Chronic rejection & $4(25.00 \%)$ \\
Autoimmune hepatitis & 3 \\
Infection & 1 \\
Pneumonia & $4(25.00 \%)$ \\
Urinary tract infection & 1 \\
\hline Cerebral vascular event (intracerebral & $2(12.50 \%)$ \\
hemorrhage) & $1(6.25 \%)$ \\
\hline Peptic ulcer bleeding &
\end{tabular}

\subsection{Predictors of Patients' Long-Term Survival}

The Cox's model fitted to the survival data for the multivariate analyses of the time to death after five years of LT is shown in Table 3. After adjusting for the effects of the other covariates, age at LT $\leq 27.011$ years (estimated hazard ratio $[H R]=168.79,95 \%$ confidence 
interval [C.I.]: 11.13-2559.51), pre-transplant autoimmune liver disease (HR $=8.12,95 \%$ C.I.: 1.97-33.43), pre-transplant HCV infection $\times$ survival time in years $(\mathrm{HR}=1.34,95 \%$ C.I.: $1.12-1.60)$, serum creatinine level $>1.311 \mathrm{mg} / \mathrm{dL} \times$ serum total bilirubin level $>1.411$ $\mathrm{mg} / \mathrm{dL}(\mathrm{HR}=921.69,95 \%$ C.I.: $43.40-19,573.71)$, serum creatinine level $>1.311 \mathrm{mg} / \mathrm{dL} \times$ serum total bilirubin level $\leq 0.792 \mathrm{mg} / \mathrm{dL}(\mathrm{HR}=105.68,95 \%$ C.I.: $7.81-1430.79)$, serum creatinine level $\leq 1.311 \mathrm{mg} / \mathrm{dL} \times$ serum total bilirubin level $>0.882 \mathrm{mg} / \mathrm{dL}(\mathrm{HR}=30.49$, 95\% C.I.: 2.98-312.34), and the mean tacrolimus trough level during the fifth year after LT $\leq 4.609 \mathrm{ng} / \mathrm{mL}$ or $>10.168 \mathrm{ng} / \mathrm{mL}(\mathrm{HR}=4.76,95 \%$ C.I.: $1.34-16.94)$ were associated with a higher long-term mortality five years after LT. The time-dependent interaction term, HCV $\times$ survival time in years, was added to the Cox's model to account for the non-proportional hazards problem between the patients with and without $\mathrm{HCV}$, and its positive-valued regression coefficient estimate, 0.292 , indicates that the risk of mortality in patients with $\mathrm{HCV}$ increases with time five years post-LT. Moreover, the three second-order interaction terms between the serum creatinine and total bilirubin levels were compared to the other two possible combinations, serum creatinine level $>1.311 \mathrm{mg} / \mathrm{dL} \times(0.792 \mathrm{mg} / \mathrm{dL}<$ serum total bilirubin level $\leq 1.411 \mathrm{mg} / \mathrm{dL}$ ) and serum creatinine level $\leq 1.311 \mathrm{mg} / \mathrm{dL} \times$ serum total bilirubin level $\leq 0.882 \mathrm{mg} / \mathrm{dL}$, as the reference group (i.e., $\mathrm{HR}=1.0$ ), where the cross sign $\times$ can be literally interpreted as "and".

Table 3. Multivariate analysis for identifying the predictors of long-term overall survival after 5 years of liver transplantations by fitting a multiple Cox's Model in the adult liver transplant recipients ${ }^{1}$.

\begin{tabular}{ccccccc}
\hline Covariate $^{2}$ & Estimate & $\begin{array}{c}\text { Standard } \\
\text { Error }\end{array}$ & $\begin{array}{c}\text { Wald's } \\
\boldsymbol{z} \text { Test }\end{array}$ & $p$ Value & $\begin{array}{c}\text { Hazard } \\
\text { Ratio (HR) }\end{array}$ & $\begin{array}{c}\text { 95\% Confidence } \\
\text { Interval (C.I.) }\end{array}$ \\
\hline Age at LT $\leq 27.011$ years & 5.1286 & 1.3872 & 3.6970 & 0.0002 & 168.7851 & $11.130-2559.512$ \\
Autoimmune (including PBC) & 2.0946 & 0.7219 & 2.9015 & 0.0037 & 8.1221 & $1.973-33.431$ \\
HCV $\times$ Overall survival years & 0.2924 & 0.0914 & 3.1978 & 0.0014 & 1.3397 & $1.120-1.603$ \\
Cre $>1.311 \times$ T-Bil $>1.411 \mathrm{mg} / \mathrm{dL}$ & 6.8262 & 1.5591 & 4.3784 & $<0.0001$ & 921.6940 & $43.401-19,573.712$ \\
Cre $>1.311 \times \mathrm{T}-\mathrm{Bil} \leq 0.792 \mathrm{mg} / \mathrm{dL}$ & 4.6604 & 1.3294 & 3.5056 & 0.0005 & 105.6778 & $7.805-1430.790$ \\
Cre $\leq 1.311 \times$ T-Bil $>0.882 \mathrm{mg} / \mathrm{dL}$ & 3.4174 & 1.1871 & 2.8788 & 0.0040 & 30.4913 & $2.977-312.341$ \\
$\quad \begin{array}{c}\text { Tacrolimus mean } \leq 4.609 \text { or } \\
\quad>10.168 \mathrm{ng} / \mathrm{mL}\end{array}$ & 1.5599 & 0.6479 & 2.4076 & 0.0161 & 4.7581 & $1.336-16.940$ \\
\hline
\end{tabular}

${ }^{1}$ The above multiple Cox's model was fitted to the 189 adult patients who underwent liver transplantations with 16 death events, for modeling the hazard rate of the right-censored overall survival time five years after liver transplantations. All the cut-off values of the continuous covariates (e.g., age at liver transplantations) were estimated by choosing the option of applying the p-spline smoothing techniques in fitting simple and multiple Cox's proportional hazards models (e.g., Figure 3). The time-dependent interaction term, $\mathrm{HCV} \times$ Overall survival year, was added to the Cox's model for handling the non-proportional hazards problem between the patients with and without $\mathrm{HCV}$, and its positive-valued regression coefficient estimate, 0.2924 , indicated that the risk of dying in the patients with HCV would increase as time elapsed five years after liver transplantations. Moreover, the three second-order interaction terms, Cre $>1.311 \times \mathrm{T}$-Bil $>1.411$, Cre $>1.311 \times \mathrm{T}$-Bil $\leq 0.792$, and Cre $\leq 1.311 \times \mathrm{T}$-Bil $>0.882$, were compared to the other two possible combinations, $\mathrm{Cre}>1.311 \times(0.792<\mathrm{T}$-Bil $\leq 1.411)$ and $\mathrm{Cre} \leq 1.311 \times \mathrm{T}$-Bil $\leq 0.882$, as the reference group (i.e., $\mathrm{HR}=1.0)$, where the cross sign $\times$ can be literally interpreted as "and." Finally, both goodness-of-fit $(\mathrm{GOF})$ measures, concordance $=0.9041(\mathrm{se}=0.0265)>0.7$ and adjusted generalized $R^{2}=0.3878>0.15$, indicated an excellent fit of this multiple Cox's model to the observed survival data. ${ }^{2}$ Abbreviations: LT, liver transplantation; PBC, primary biliary cirrhosis; HCV, hepatitis C viral infection; Cre, serum creatinine level (mg/dL); T-Bil, serum total bilirubin level (mg/dL); and Tacrolimus mean, the averaged dosage of the tacrolimus-based immunosuppressant $(\mathrm{ng} / \mathrm{mL})$.

All cut-off values of the continuous covariates (such as age at LT) were estimated by applying the p-spline smoothing techniques in fitting simple and multiple Cox's proportional hazards models. As shown in Figure 3, the optimal cut-off values of the mean tacrolimus trough level, $4.609 \mathrm{ng} / \mathrm{mL}$ and $10.168 \mathrm{ng} / \mathrm{mL}$, were estimated directly in the "p-spline plot," which allowed the visualization of the nonlinear effect of the averaged dosage of the tacrolimus-based immunosuppressant during the fifth year after LT on $\log (\lambda)$, where $\lambda$ was the hazard rate of time to death five years after LT. Then, the Kaplan-Meier estimates of survival curves for time to death five years after LT were determined for the 66 patients with mean tacrolimus trough levels $\leq 4.609 \mathrm{ng} / \mathrm{mL}$ or $>10.168 \mathrm{ng} / \mathrm{mL}$ and the 123 patients with mean tacrolimus trough levels between $4.609 \mathrm{ng} / \mathrm{mL}$ and $10.168 \mathrm{ng} / \mathrm{mL}$ (log-rank test, $p=0.009$ ) (Figure 4). In an additional subgroup analysis, we found that a mean tacrolimus trough level between $4.431 \mathrm{ng} / \mathrm{mL}$ and $6.332 \mathrm{ng} / \mathrm{mL}$ for patients with a 
serum creatinine level $>1.311 \mathrm{mg} / \mathrm{dL}$ improved survival. Finally, this Cox's model had a concordance of 0.904 and an adjusted generalized $R^{2}$ of 0.388 , indicating that it fit the survival data very well.

Box Plot of the FK Mean Stratified by the Cause of Death $(n=16)$

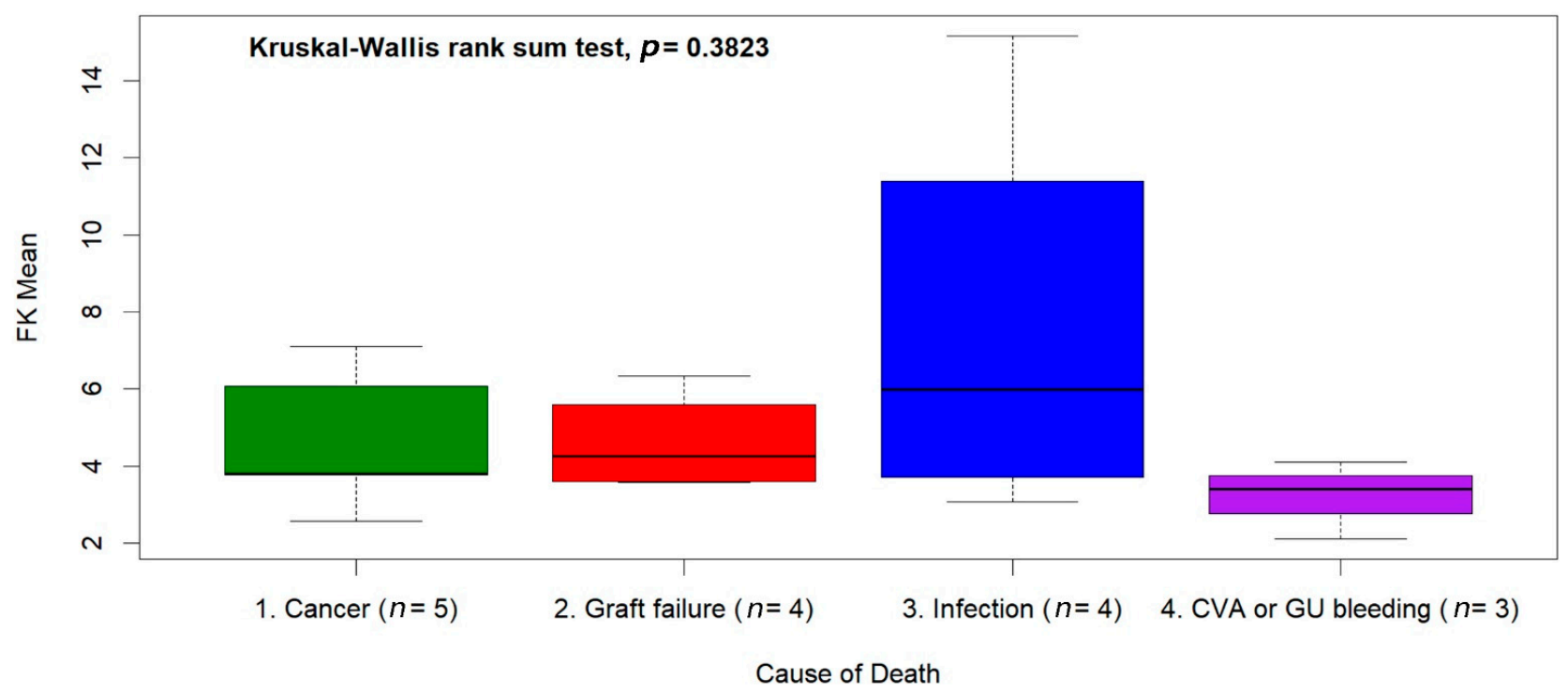

Figure 2. The box plot of tacrolimus mean trough level stratified by the etiology and cause of death among the 16 dead patients. There was no statistical difference of tacrolimus level between the different causes of death $(p=0.3823)$.

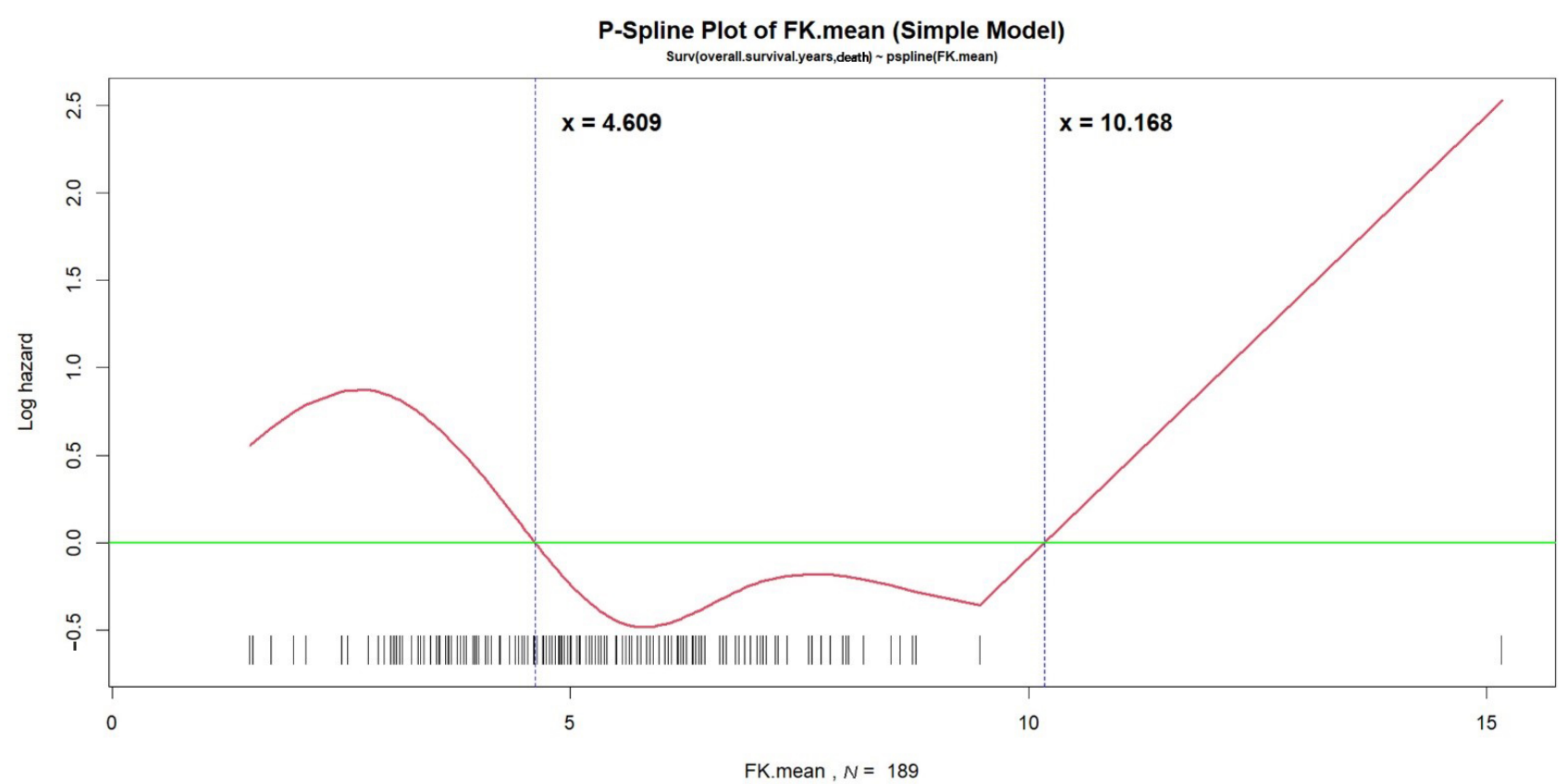

Figure 3. The p-spline plot for the nonlinear effect of the long-term tacrolimus blood trough levels on time to death. The tacrolimus blood trough level is shown on the $X$-axis, and the $\log (\lambda)$, where $\lambda$ is the hazard rate of time to death five years after liver transplantation, is shown on the $Y$-axis. In this $p$-spline plot, the intersection between the horizontal green line $(Y=0)$ and the red curve yields the estimated optimal cut-off values for long-term tacrolimus blood trough levels at which the values of $\log (\lambda)$ will not change $(4.609 \mathrm{ng} / \mathrm{mL}$ and $10.168 \mathrm{ng} / \mathrm{mL})$. When the level is $\leq 4.609 \mathrm{ng} / \mathrm{mL} \mathrm{or}>10.168 \mathrm{ng} / \mathrm{mL}$, the value of $\log (\lambda)$ increases, indicating an increasing $\lambda$. When the level is $>4.609 \mathrm{ng} / \mathrm{mL}$ and $\leq 10.168 \mathrm{ng} / \mathrm{mL}$, the value of $\log (\lambda)$ decreases, indicating a decreasing $\lambda$. The vertical bars above the $X$-axis represent the patients' actual mean tacrolimus blood trough levels obtained at the three follow-up visits during the fifth year after LT. 
The Kaplan-Meier Estimate of Survival Curve for Time to Death after 5 Years of Liver Transplantations Stratified by Tacrolimus

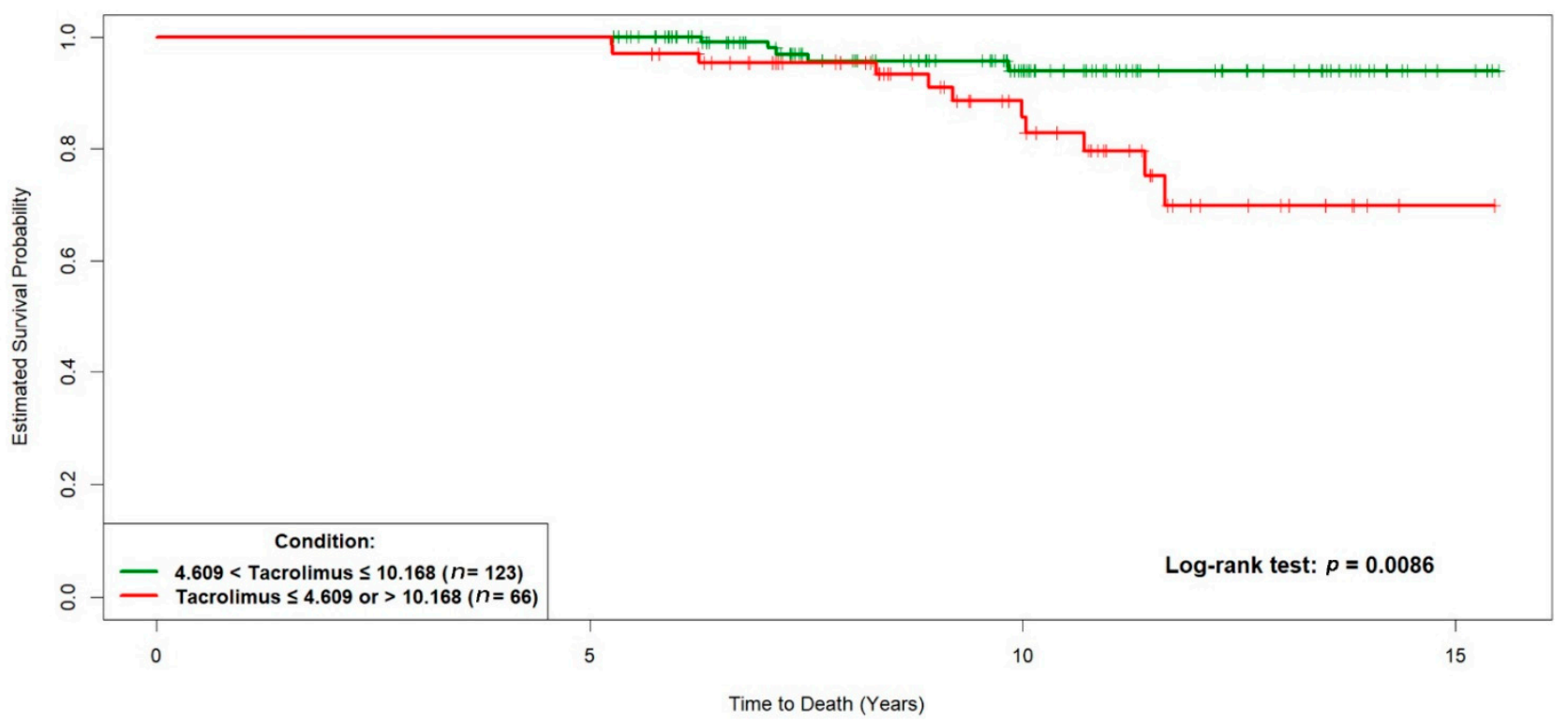

Figure 4. The Kaplan-Meier curve for time to death five years after liver transplantation. The survival curve of the 66 patients with a mean tacrolimus blood trough level $\leq 4.609 \mathrm{ng} / \mathrm{mL}$ or $>10.168 \mathrm{ng} / \mathrm{mL}$ is shown in red while the survival curve of the 123 patients with a mean tacrolimus blood trough level $>4.609 \mathrm{ng} / \mathrm{mL}$ or $\leq 10.168 \mathrm{ng} / \mathrm{mL}$ is shown in green.

\section{Discussion}

This is the first study to report an association between long-term tacrolimus blood trough level and long-term patient survival in adult LT recipients. We found that a longterm tacrolimus blood trough level of $4.6-10.2 \mathrm{ng} / \mathrm{mL}$ in adult LT recipients is associated with a lower mortality rate. In patients with a serum creatinine $>1.3 \mathrm{mg} / \mathrm{dL}$, a mean tacrolimus blood trough level of $4.4-6.3 \mathrm{ng} / \mathrm{mL}$ is associated with a lower mortality rate.

Decreasing tacrolimus use during long-term follow-up in LT recipients is a general concept in clinical practice. In this study, only one patient had the mean level $>10 \mathrm{ng} / \mathrm{mL}$ and a few patients had the mean level $>8 \mathrm{ng} / \mathrm{mL}$ (Figure 3). Patients with such high drug levels were most likely because of their poor compliance (not must because of they have truly such high trough level). Poor compliance indicates that a patient takes incorrect dosage of immunosuppressant that their physician prescribed, or takes immunosuppressant or blood exam at the wrong time, either of which might clearly be important factors that influence graft and survival outcome of LT patients during long-term follow-ups. We found that a long-term tacrolimus blood trough level of $4.6-10.2 \mathrm{ng} / \mathrm{mL}$ is associated with lower mortality rate; however, the upper limit of $10.2 \mathrm{ng} / \mathrm{mL}$ suggested by the regression analysis was merely a value for caution, but not a recommended upper limit in real clinical practice. The long-term hazard of high level of tacrolimus is already widely known; therefore, we would focus more on the findings that it appears to increase the survival risks in LT recipients if their tacrolimus levels are maintained below $4.6 \mathrm{ng} / \mathrm{mL}$ during the long-term follow-ups.

Inadequate immunosuppression is associated with higher risks of graft rejection [19], while excess immunosuppression increases the risks of malignancy and infection and increases the adverse effects of drug toxicity. The tailored use of immunosuppressants should be considered based on the patient's risks of graft rejection and infection and the patient's medical comorbidities and liver disease status prior to LT [14]. Patients with autoimmune liver diseases may require more immunosuppression to prevent disease recurrence and graft rejection [20]. By contrast, lower doses of immunosuppression are recommended in 
patients who have undergone LT due to $\mathrm{HCV}$, as high levels of immunosuppression are related to increased viral replication [21,22]. Rejection results in abnormal liver function and is one of the most important factors associated with poor long-term graft and patient outcomes [23-25]. Tacrolimus reduces the risk of T-cell mediated rejection to protect graft function and is the cornerstone of a successful LT. However, short and long-term adverse effects of tacrolimus such as infection, chronic renal insufficiency, metabolic diseases (hyperlipidemia, hypertension, and diabetes mellitus), and malignancy have been widely reported and influence patients" long-term outcomes [7-9]. The early causes of death after LT within one year are infection and graft loss, and the late causes of death three years post-LT are malignancy, cardiovascular disease, and renal failure [10]. As graft function typically stabilizes, factors associated with the long-term outcome are often patient-related factors (such as chronic medical diseases) that are usually associated with tacrolimus.

Previous studies have reported that minimizing tacrolimus use in the early post-LT period is associated with a lower risk of new-onset diabetes mellitus [26], a lower incidence of hyperlipidemia [27], and better long-term survival $[19,28]$. In recent years, studies have focused on the reduction or complete withdrawal of long-term immunosuppressants in LT recipients [12,29-34]. One study reported satisfactory outcomes with the combined use of tacrolimus and mycophenolate mofetil, which allowed for the tacrolimus dose to be reduced [35]. Other studies demonstrated that the concomitant use of everolimus may reduce the required dose of tacrolimus while having potential renal benefits $[29,36]$. However, only some LT recipients were able to discontinue the use of immunosuppressants, and these patients more frequently experienced biopsy-proven acute rejection [29]. The risk of chronic rejection during long-term follow-up remains in patients with inadequate immunosuppression $[30,33]$. The tacrolimus blood concentration in LT recipients may play a key role in long-term outcomes, as it is associated with long-term graft function and its adverse effects are related to several chronic medical diseases. However, to the best of our knowledge, this is the first report regarding the effect of long-term tacrolimus levels on the long-term survival outcomes of LT recipients.

Several factors are associated with the long-term outcomes of adult LT recipients, including pre-transplant primary sclerosing cholangitis, immunosuppression therapies, acute and chronic rejections, malignancy, and metabolic syndrome [37,38]. As listed in Table 3, we found several independent risk factors of long-term mortality in this study. Only four patients aged $<27$ years at the time of LT were included in this study, and one died due to pneumonia 6.3 years after LT. Patients who underwent LT due to autoimmune liver diseases had worse outcomes, as they were more likely to experience acute rejections [39] and suffer disease recurrence, leading to graft loss. Patients who underwent LT due to HCV infections had relatively poor post-LT outcomes due to the disease recurrence followed by graft dysfunction and failure [40]. As direct-acting antiviral agents have advanced [41], the survival outcomes of HCV patients should improve in the near future. Long-term renal and liver functions are reflected by serum creatinine and total bilirubin levels, respectively. We found that abnormal serum creatinine levels have a bigger impact than abnormal serum total bilirubin levels on the survival outcomes of LT recipients. The graft function of adult LT recipients is chronically stable five years after LT. While some patients may experience asymptomatic hyperbilirubinemia at this time, the long-term outcomes remain favorable. By contrast, the gradual deterioration of renal function may lead to chronic kidney disease or end-stage renal disease, affecting the long-term survival, especially in patients with long-term use of tacrolimus.

This study had some limitations. First, the data were obtained from a single medical center in Asia, which provided a relatively small number of eligible patients with single ethnicity and fewer death events. Second, the study spanned a long time period, and therefore the improvements in surgical and medical expertise and advances in immunosuppression therapies may have influenced the patient outcomes. Third, we did not collect or analyze the time-dependent tacrolimus blood trough level during the follow-up visits five years after LT. 
In summary, we found an association between the long-term tacrolimus blood trough levels and the long-term survival five years after LT. A mean tacrolimus blood trough level outside the range of 4.6-10.2 $\mathrm{ng} / \mathrm{mL}$ appeared to be an independent risk factor for longterm mortality. Further studies with larger sample sizes are needed to verify these results and to further identify an appropriate tacrolimus blood trough level for maintenance use.

Author Contributions: C.-Y.H. drafted the manuscript and R.-H.H. designed the study. C.-Y.H., M.-C.H., and Y.-M.W. conducted data processing, and C.-Y.H. and C.-M.H. performed data analysis. P.-H.L. and R.-H.H. were the directors responsible for general organization and instruction. All authors have read and agreed to the published version of the manuscript.

Funding: This research received no external funding.

Institutional Review Board Statement: The study was conducted according to the guidelines of the Declaration of Helsinki, and approved by the Institutional Review Board of National Taiwan University Hospital.

Informed Consent Statement: Patient consent was waived due to retrospective design of the study.

Data Availability Statement: The datasets used and analyzed during the current study are available from the corresponding author upon reasonable request.

Acknowledgments: We thank the coordinators (Hui-Ying Lin and Min-Heuy Lin) for their helpful efforts in data collection.

Conflicts of Interest: The authors declare no conflict of interest.

\section{References}

1. Adam, R.; Karam, V.; Delvart, V.; O'Grady, J.; Mirza, D.; Klempnauer, J.; Burroughs, A. Evolution of indications and results of liver transplantation in Europe. A report from the European Liver Transplant Registry (ELTR). J. Hepatol. 2012, 57, 675-688. [CrossRef] [PubMed]

2. Fung, J.; Kelly, D.; Kadry, Z.; Patel-Tom, K.; Eghtesad, B. Immunosuppression in liver transplantation: Beyond calcineurin inhibitors. Liver Transpl. 2005, 11, 267-280. [CrossRef] [PubMed]

3. European Association for the Study of the Liver. Electronic address EEE. EASL Clinical Practice Guidelines: Liver transplantation. J. Hepatol. 2016, 64, 433-485. [CrossRef] [PubMed]

4. Wiesner, R.H.; Fung, J.J. Present state of immunosuppressive therapy in liver transplant recipients. Liver Transpl. 2011, 17 (Suppl. 3), S1-S9. [CrossRef] [PubMed]

5. McAlister, V.C.; Haddad, E.; Renouf, E.; Malthaner, R.A.; Kjaer, M.S.; Gluud, L.L. Cyclosporin versus tacrolimus as primary immunosuppressant after liver transplantation: A meta-analysis. Am. J. Transplant. 2006, 6, 1578-1585. [CrossRef]

6. O'Grady, J.G.; Hardy, P.; Burroughs, A.K.; Elbourne, D.; UK and Ireland Liver Transplant Study Group. Randomized controlled trial of tacrolimus versus microemulsified cyclosporin (TMC) in liver transplantation: Poststudy surveillance to 3 years. Am. J. Transplant. 2007, 7, 137-141. [CrossRef]

7. Gonwa, T.A.; Mai, M.L.; Melton, L.B.; Hays, S.R.; Goldstein, R.M.; Levy, M.F. End-stage renal disease (ESRD) after orthotopic liver transplantation (OLTX) using calcineurin-based immunotherapy: Risk of development and treatment. Transplantation 2001, 72, 1934-1939. [CrossRef]

8. Dantal, J.; Soulillou, J.P. Immunosuppressive drugs and the risk of cancer after organ transplantation. N. Engl. J. Med. 2005, 352, 1371-1373. [CrossRef]

9. Halloran, P.F. Immunosuppressive drugs for kidney transplantation. N. Engl. J. Med. 2004, 351, 2715-2729. [CrossRef]

10. Watt, K.D.; Pedersen, R.A.; Kremers, W.K.; Heimbach, J.K.; Charlton, M.R. Evolution of causes and risk factors for mortality post-liver transplant: Results of the NIDDK long-term follow-up study. Am. J. Transplant. 2010, 10, 1420-1427. [CrossRef]

11. Benitez, C.; Londono, M.C.; Miquel, R.; Manzia, T.M.; Abraldes, J.G.; Lozano, J.J. Prospective multicenter clinical trial of immunosuppressive drug withdrawal in stable adult liver transplant recipients. Hepatology 2013, 58, 1824-1835. [CrossRef] [PubMed]

12. Londono, M.C.; Rimola, A.; O'Grady, J.; Sanchez-Fueyo, A. Immunosuppression minimization vs. complete drug withdrawal in liver transplantation. J. Hepatol. 2013, 59, 872-879. [CrossRef] [PubMed]

13. Lucey, M.R.; Terrault, N.; Ojo, L.; Hay, J.E.; Neuberger, J.; Blumberg, E. Long-term management of the successful adult liver transplant: 2012 practice guideline by the American Association for the Study of Liver Diseases and the American Society of Transplantation. Liver Transpl. 2013, 19, 3-26. [CrossRef] [PubMed]

14. Neuberger, J.M.; Bechstein, W.O.; Kuypers, D.R.; Burra, P.; Citterio, F.; De Geest, S.; Duvoux, C.; Jardine, A.G.; Kamar, N.; Krämer, B.K.; et al. Practical Recommendations for Long-term Management of Modifiable Risks in Kidney and Liver Transplant Recipients: A Guidance Report and Clinical Checklist by the Consensus on Managing Modifiable Risk in Transplantation (COMMIT) Group. Transplantation 2017, 101 (Suppl. 2), S1-S56. [CrossRef] [PubMed] 
15. Charlton, M.; Levitsky, J.; Aqel, B.; O'Grady, J.; Hemibach, J.; Rinella, M.; Saliba, F. International Liver Transplantation Society Consensus Statement on Immunosuppression in Liver Transplant Recipients. Transplantation 2018, 102, 727-743. [CrossRef]

16. $\mathrm{Hu}$, F.C. My Stepwise: Stepwise Variable Selection Procedures for Regression Analysis. R Package, Version 0.1.0. Available online: https: / /CRAN.R-project.org/package=My.stepwise (accessed on 12 October 2020).

17. Nagelkerke, N. A note on a general definition of the coefficient of determination. Biometrika 1991, 78, 691-692. [CrossRef]

18. Moore, D.F. Applied Survival Analysis Using R; Springer International Publishing: Cham, Switzerland, 2016 ; pp. 84-85.

19. Rodriguez-Peralvarez, M.; Germani, G.; Papastergiou, V.; Tsochatzis, E.; Thalassinos, E.; Luong, T.V. Early tacrolimus exposure after liver transplantation: Relationship with moderate/severe acute rejection and long-term outcome. J. Hepatol. 2013, 58, 262-270. [CrossRef]

20. Khalaf, H.; Mourad, W.; El-Sheikh, Y.; Abdo, A.; Helmy, A.; Medhat, Y. Liver transplantation for autoimmune hepatitis: A single-center experience. Transplant. Proc. 2007, 39, 1166-1170. [CrossRef]

21. Grassi, A.; Ballardini, G. Post-liver transplant hepatitis C virus recurrence: An unresolved thorny problem. World J. Gastroenterol. 2014, 20, 11095-11115. [CrossRef]

22. Moini, M.; Schilsky, M.L.; Tichy, E.M. Review on immunosuppression in liver transplantation. World J. Hepatol. 2015, 7, 1355-1368. [CrossRef]

23. Adams, D.H.; Neuberger, J.M. Patterns of graft rejection following liver transplantation. J. Hepatol. 1990, 10, 113-119. [CrossRef]

24. Mor, E.; Gonwa, T.A.; Husberg, B.S.; Goldstein, R.M.; Klintmalm, G.B. Late-onset acute rejection in orthotopic liver transplantationassociated risk factors and outcome. Transplantation 1992, 54, 821-824. [CrossRef] [PubMed]

25. Thurairajah, P.H.; Carbone, M.; Bridgestock, H.; Thomas, P.; Hebbar, S.; Gunson, B.K.; Shah, T.; Neuberger, J. Late acute liver allograft rejection; a study of its natural history and graft survival in the current era. Transplantation 2013, 95, 955-959. [CrossRef] [PubMed]

26. Song, J.L.; Gao, W.; Zhong, Y.; Yan, L.N.; Yang, J.Y.; Wen, T.F.; Yang, J. Minimizing tacrolimus decreases the risk of new-onset diabetes mellitus after liver transplantation. World J. Gastroenterol. 2016, 22, 2133-2141. [CrossRef] [PubMed]

27. Li, H.Y.; Li, B.; Wei, Y.G.; Yan, L.N.; Wen, T.F.; Zhao, J.C. Higher tacrolimus blood concentration is related to hyperlipidemia in living donor liver transplantation recipients. Dig. Dis. Sci. 2012, 57, 204-209. [CrossRef] [PubMed]

28. Jia, J.J.; Lin, B.Y.; He, J.J.; Geng, L.; Kadel, D.; Wang, L.; Yu, D.-D.; Shen, T.; Yang, Z.; Ye, Y.-F.; et al. "Minimizing tacrolimus" strategy and long-term survival after liver transplantation. World J. Gastroenterol. 2014, 20, 11363-11369. [CrossRef] [PubMed]

29. Saliba, F.; Duvoux, C.; Gugenheim, J.; Kamar, N.; Dharancy, S.; Salame, E. Efficacy and Safety of Everolimus and Mycophenolic Acid with Early Tacrolimus Withdrawal after Liver Transplantation: A Multicenter Randomized Trial. Am. J. Transplant. 2017, 17, 1843-1852. [CrossRef] [PubMed]

30. Girlanda, R.; Rela, M.; Williams, R.; O'Grady, J.G.; Heaton, N.D. Long-term outcome of immunosuppression withdrawal after liver transplantation. Transplant. Proc. 2005, 37, 1708-1709. [CrossRef]

31. Oike, F.; Yokoi, A.; Nishimura, E.; Ogura, Y.; Fujimoto, Y.; Kasahara, M. Complete withdrawal of immunosuppression in living donor liver transplantation. Transplant. Proc. 2002, 34, 1521. [CrossRef]

32. Mazariegos, G.V.; Reyes, J.; Marino, I.R.; Demetris, A.J.; Flynn, B.; Irish, W.; Starzl, T.E. Weaning of immunosuppression in liver transplant recipients. Transplantation 1997, 63, 243-249. [CrossRef]

33. Takatsuki, M.; Uemoto, S.; Inomata, Y.; Egawa, H.; Kiuchi, T.; Fujita, S.; Hayashi, M.; Kanematsu, T.; Tanaka, K. Weaning of immunosuppression in living donor liver transplant recipients. Transplantation 2001, 72, 449-454. [CrossRef] [PubMed]

34. Tisone, G.; Orlando, G.; Cardillo, A.; Palmieri, G.; Manzia, T.M.; Baiocchi, L. Complete weaning off immunosuppression in HCV liver transplant recipients is feasible and favourably impacts on the progression of disease recurrence. J. Hepatol. 2006, 44, 702-709. [CrossRef] [PubMed]

35. Boudjema, K.; Camus, C.; Saliba, F.; Calmus, Y.; Salame, E.; Pageaux, G.; Ducerf, C.; Duvoux, C.; Mouchel, C.; Renault, A.; et al. Reduced-dose tacrolimus with mycophenolate mofetil vs. standard-dose tacrolimus in liver transplantation: A randomized study. Am. J. Transplant. 2011, 11, 965-976. [CrossRef] [PubMed]

36. Fischer, L.; Saliba, F.; Kaiser, G.M.; De Carlis, L.; Metselaar, H.J.; De Simone, P. Three-year Outcomes in De Novo Liver Transplant Patients Receiving Everolimus with Reduced Tacrolimus: Follow-Up Results from a Randomized, Multicenter Study. Transplantation 2015, 99, 1455-1462. [CrossRef] [PubMed]

37. Imai, D.; Yoshizumi, T.; Sakata, K.; Ikegami, T.; Itoh, S.; Harada, N.; Maehara, Y. Long-Term Outcomes and Risk Factors after Adult Living Donor Liver Transplantation. Transplantation 2018, 102, e382-e391. [CrossRef] [PubMed]

38. Durand, F. How to improve long-term outcome after liver transplantation? Liver Int. 2018, 38 (Suppl. 1), 134-138. [CrossRef]

39. Edmunds, C.; Ekong, U.D. Autoimmune Liver Disease Post-Liver Transplantation: A Summary and Proposed Areas for Future Research. Transplantation 2016, 100, 515-524. [CrossRef]

40. Pruthi, J.; Medkiff, K.A.; Esrason, K.T.; Donovan, J.A.; Yoshida, E.M.; Erb, S.R.; Steinbrecher, U.P.; Fong, T.-L. Analysis of causes of death in liver transplant recipients who survived more than 3 years. Liver Transpl. 2001, 7, 811-815. [CrossRef]

41. Suraweera, D.; Sundaram, V.; Saab, S. Treatment of Hepatitis C Virus Infection in Liver Transplant Recipients. Gastroenterol. Hepatol. (N. Y.) 2016, 12, 23-30. 